\title{
Antitumor activity of polysaccharide extracted from Pleurotus ostreatus mycelia against gastric cancer in vitro and in vivo
}

\author{
XIANG-YU CAO, JIAN-LI LIU, WEI YANG, XIAO HOU and QI-JIU LI \\ School of Life Science, Liaoning University, Shenyang, Liaoning 110036, P.R. China
}

Received June 25, 2014; Accepted March 18, 2015

DOI: $10.3892 / \mathrm{mmr} .2015 .3648$

\begin{abstract}
The present study aimed to determine the antitumor effects of polysaccharides extracted from Pleurotus ostreatus mycelium on gastric cancer in vitro and in vivo. Polysaccharides were extracted from Pleurotus ostreatus mycelium and an antitumor component, known as Pleurotus ostreatus mycelium polysaccharides 2 (POMP2), with a relative molecular weight of $29 \mathrm{kDa}$, was then sequentially purified using Sephadex G200 size-exclusion chromatography and diethylaminoethyl-52 cellulose ion-exchange chromatography. The MTT method was used to determine the proliferation of BGC-823 cells treated with POMP2; cell migration assay, colony formation assay and in vivo antitumor tests were used to assess the effect of POMP2 on migration, cell survival and the in vivo tumor formation of BGH-823 cells. Results of the MTT assay indicated that POMP2 had a marked inhibitory effect on the BGC-823 human gastric cancer cell line; when administered at a concentration of $400 \mathrm{mg} / \mathrm{l}$ for $72 \mathrm{~h}$, the rate of inhibition was $35.6 \%$. In addition, the colony forming capacity of the BGC-823 cells was significantly reduced following treatment with POMP2. A migration assay indicated that the invasive capabilities of the BGC-823 cells were also significantly inhibited by POMP2. Furthermore, in vivo tests of mice engrafted with BGC-823 cancer cells demonstrated that both tumor weight and volume were markedly reduced following two weeks of treatment with POMP2. The results of the present study suggested that the polysaccharide POMP2 may have a potential application as a natural antitumor treatment for gastric cancer.
\end{abstract}

Correspondence to: Dr Jian-Li Liu, School of Life Science, Liaoning University, 66 Chongshan Middle Road, Shenyang, Liaoning 110036, P.R. China

E-mail: liujianli119@163.com

Abbreviations: POMP2, Pleurotus ostreatus mycelium polysaccharides 2; MTT, 3-(4,5-dimethylthiazol-2-yl)-2,5-dipheny ltetrazolium bromide; 5-FU, 5-fluorouracil; FBS, fetal bovine serum

Key words: Pleurotus ostreatus mycelia, polysaccharide, antitumor, gastric cancer

\section{Introduction}

Gastric cancer is one of the most prevalent types of cancer and is the second leading cause of cancer-associated mortality worldwide, with approximately one million novel cases diagnosed annually (1-3). Gastric cancer is highly prevalent in Asia, particularly in China, Japan and Korea, as well as in Eastern Europe and parts of Central and South America (4); however, a marked decline has been reported in the incidence and mortality of gastric cancer (5). There are two major types of gastric adenocarcinoma: Intestinal and diffuse. The pathogenesis of intestinal gastric adenocarcinoma was reported to be a progression from chronic gastritis to gastric atrophy and dysplasia through multiple steps, whereas the pathogenesis of diffuse-type gastric cancer remains to be fully elucidated (6). Currently, the most widely accepted cause for diffuse-type gastric cancer is Helicobacter pylori infection (6). Conventional treatment options for gastric cancer include pharmacotherapy, surgical resection, chemotherapy and radiation therapy. Surgical resection remains the only curative treatment option; however, it may only be performed in a small subgroup of patients $(7,8)$. Furthermore, even post surgery, numerous patients will experience disease recurrence and succumb within a few months or years (8). In addition, the majority of chemotherapeutic drugs currently on the market induce various side effects. Therefore, the production of effective and non-toxic biological drugs is urgently required.

Mushrooms have been utilized as edible and medicinal resources; numerous bioactive molecules have been identified from their fruit body and cultured mycelium, which exhibit various biological activities, including antitumor and immunomodulating properties $(9,10)$. Polysaccharides possess the highest potential of the mushroom-derived substances that exhibit antitumor properties $(10,11)$. Polysaccharides are polymers comprised of monosaccharides linked together through glycosidic bonds (12). Over the past few decades, numerous types of antitumor polysaccharides have been identified from various sources and the mechanisms underlying their activity have been elucidated. More recent research has focused on identifying novel polysaccharides (13-16). Pleurotus ostreatus is a common edible mushroom, which is cultured commercially around the world for food. It is frequently used in Chinese, Japanese and Korean cookery, due to its flavor, high nutritional 
value and various medicinally beneficial effects $(17,18)$. Previous studies have demonstrated that polysaccharides extracted from Pleurotus ostreatus possess antitumor properties $(19,20)$; however, to the best of our knowledge no studies regarding the antitumor activity of Pleurotus ostreatus mycelia polysaccharides on gastric cancer have been published.

The aim of the present study was to extract polysaccharides from Pleurotus ostreatus mycelia, which had been harvested from submerged cultures, and analyze their antitumor effects on gastric cancer in vitro and in vivo. The present study aimed to provide a scientific basis for research and reasonable application of polysaccharides in biological drugs.

\section{Materials and methods}

Materials and reagents. Pleurotus ostreatus (strain, beiping 11) was maintained at the School of Life Science, Liaoning University (Shenyang, China). MTT, penicillin, streptomycin and 5-fluorouracil (5-FU) were purchased from Sigma-Aldrich (St. Louis, MO, USA). Diethylaminoethyl (DEAE)-52 and Sephadex G-200 were purchased from GE Healthcare (Uppsala, Sweden). Fetal bovine serum (FBS) and RPMI-1640 media were purchased from Gibco Life Technologies (Grand Island, NY, USA). All other chemical reagents were analytical reagent grade, and were purchased from Sigma-Aldrich (St. Louis, MO, USA) unless otherwise specified.

The BGC-823 human gastric cancer cells were obtained from China Medical University (Shenyang, China). The cells were cultured in RPMI-1640 medium supplemented with $10 \%$ FBS, penicillin $(100 \mathrm{U} / \mathrm{ml})$ and streptomycin $(100 \mu \mathrm{g} / \mathrm{ml})$ at $37^{\circ} \mathrm{C}$ in a humidified atmosphere containing $5 \% \mathrm{CO}_{2}$. The cells were harvested once they had reached the exponential growth phase. All procedures involving animals and their care were conducted in accordance with institutional guidelines for the Laboratory Animal Care of Experimental Animal Center, China Medical University.

Fungal cultivation and extraction of crude polysaccharides. The fungus was maintained at $25^{\circ} \mathrm{C}$ on a potato dextrose agar plate for 6 days in an incubator. The active mycelium were then scraped and transferred to a $250 \mathrm{ml}$ Erlenmeyer flask containing $100 \mathrm{ml}$ of $200 \mathrm{~g} / 1$ potato, $20 \mathrm{~g} / 1$ glucose, $3 \mathrm{~g} / \mathrm{l}$ yeast extract, $1 \mathrm{~g} / 1 \mathrm{KH}_{2} \mathrm{PO}_{4}$ and $1 \mathrm{~g} / 1 \mathrm{MgSO}_{4}$ with natural $\mathrm{pH}$, and were cultured for 7 days at $25^{\circ} \mathrm{C}$ with $160 \mathrm{rpm}$ agitation (13). Pleurotus ostreatus mycelia were harvested from the liquid medium by centrifuging the culture at 7,500 $\mathrm{x}$ g for $20 \mathrm{~min}$ at $4^{\circ} \mathrm{C}$. The mycelia were then dried in a $60^{\circ} \mathrm{C}$ oven. The dried fungal biomass was ground and boiled in water for $4 \mathrm{~h}$. The supernatant was treated with four volumes of absolute ethanol $(4: 1 \mathrm{v} / \mathrm{v})$ at $4^{\circ} \mathrm{C}$ for $12 \mathrm{~h}$ following centrifugation at 7,500 $\mathrm{x}$ g for $30 \mathrm{~min}$ in order to extract the crude polysaccharides (10). The sediment was washed with absolute ethanol following centrifugation at 7,500 $\mathrm{x}$ g for $20 \mathrm{~min}$, centrifuged and washed with absolute ethanol a further two times. Protein was removed from the crude polysaccharide by Sevage method (21) and then dialyzed with distilled water. During the Sevage method, the polysaccharides were mixed with Sevage reagent, 5:1 (v:v) $\mathrm{CHCl}_{3}, \mathrm{n}-\mathrm{BuOH}$ and stirred for $30 \mathrm{~min}$. The mixture was then centrifuged at $7,500 \mathrm{x} \mathrm{g}$ for $20 \mathrm{~min}$, the upper polysaccharide solution was collected and then dialyzed with distilled water (21). The solution was precipitated with absolute ethanol and maintained at $4^{\circ} \mathrm{C}$ for $4 \mathrm{~h}$. The precipitate was freeze-dried following centrifugation at 7,500 $\mathrm{xg}$ for $20 \mathrm{~min}(22)$.

Purification of Pleurotus ostreatus mycelium polysaccharides. The crude polysaccharides $(0.5 \mathrm{~g})$ were dissolved in distilled water $(10 \mathrm{ml})$ and applied to a Sephadex G-200 column $(2.0 \times 60.0 \mathrm{~cm})$. The sample was eluted with $0.15 \mathrm{M}$ sodium chloride at a flow rate of $1 \mathrm{ml} / \mathrm{min}$. Fractions were collected and carbohydrates were measured using the anthrone-sulphuric acid method (23). In brief, $1 \mathrm{ml}$ solution and $5 \mathrm{ml}$ anthrone reagent $(0.1 \mathrm{~g}$ anthrone dissolved in $100 \mathrm{ml}$ sulphuric acid solution) were placed in a water bath (boiling) for $10 \mathrm{~min}$, cooled and measured using a UV-Vis spectrophotometer (GBC Cintra 20; GBC Scientific Equipment, Melbourne, Australia) at $620 \mathrm{~nm}$. The sugar content was calculated using a standard curve created with standardized glucose solutions. Further purification was conducted using a DEAE-52 column $(2.5 \times 40.0 \mathrm{~cm})$, sodium chloride solution was used as the mobile phase and the samples were eluted in gradient mode at a flow rate of $1 \mathrm{ml} / \mathrm{min}$. The fractions were collected by the automated fraction collector (AFC-3000 Automated Fraction Collector; Thermo Fisher Scientific, Waltham, MA, USA) and measured at $620 \mathrm{~nm}$ absorbance using the UV-Vis spectrophotometer, as recommended by the anthrone-sulphuric acid method. The collected fractions were dialyzed in distilled water for $24 \mathrm{~h}$ and freeze-dried to obtain three types of purified polysaccharides: Pleurotus ostreatus mycelium polysaccharides (POMP1, POMP2 and POMP3). An MTT assay was performed (as described in the 'BGC-823 cell proliferation assay' paragraph) to evaluate the antitumor activity of the three polysaccharides, following which POMP2 was selected for use in the subsequent studies.

Preliminary characterization of polysaccharides. The molecular weight of POMP2 was determined by high performance gel permeation chromatography (HPGPC) as described by Miao et al (24) with minor modifications. The sample was applied to an Agilent 1100 high performance liquid chromatography system (Agilent Technologies, Santa Clara, CA, USA) equipped with a TSK-GEL G3000 PWXL column $(7.8 \times 300 \mathrm{~mm})$. The sample was eluted with $0.1 \mathrm{~mol} / 1 \mathrm{Na}_{2} \mathrm{SO}_{4}$ solution at a flow rate of $0.5 \mathrm{ml} / \mathrm{min}$ and was detected using a Refractive Index Detector-10A (Shimadzu Corporation, Tokyo, Japan). The molecular weight was estimated with reference to a calibration curve generated from a Dextran T-series standard of known molecular weights ( $\mathrm{Mw}$; T-200, T-100, T-40, T-20 and T-10) and glucose (Mw, 180; Sigma-Aldrich) was used as a standard (19). The sample was detected using the UV spectrophotometer at 280 and $260 \mathrm{~nm}$, in order to confirm the absence of protein and nucleic acid.

BGC-823 cell proliferation assay. BGC- 823 cells $\left(1 \times 10^{4}\right)$ were grown on 96 -well plates (100 $\mu \mathrm{l} /$ well). Following a $24 \mathrm{~h}$ incubation, non-adherent cells were removed by washing with RPMI-1640 medium three times. The cultures were treated with a serial concentration of POMP $2(25,50,100$, 200 and $400 \mathrm{mg} / \mathrm{l})$ and MTT $(5 \mathrm{mg} / \mathrm{ml})$ was added to each well following 24,48 or $72 \mathrm{~h}$. The plate was incubated for 
an additional $4 \mathrm{~h}$ at $37^{\circ} \mathrm{C}$, following which the medium was discarded. Subsequently, the formazan crystals were dissolved in $150 \mu 1$ dimethyl sulfoxide. In order to evaluate the proliferative ability of the BGC- 823 cells, MTT reduction was determined by measuring the light absorbance of each well at $490 \mathrm{~nm}$ using a microplate reader (680; Bio-Rad Laboratories, Inc., Hercules, CA, USA). All experiments were repeated in triplicate (25).

Cell migration assay. Cell migration assays are frequently used to assess the migration of metastatic cancer cells. The migration assay was performed using a $6.5 \mathrm{~mm}$-diameter Transwell chamber (Corning Life Sciences, Tewksbury, MA, USA) with an $8.0 \mu \mathrm{m}$ pore size. The BGC-823 cells were trypsinized $(0.25 \%$ trypsin) and resuspended in serum-free RPMI-1640 following serum-starvation for $24 \mathrm{~h}$. Approximately $1 \times 10^{5}$ cells in serum-free RPMI-1640, with 100 or $200 \mathrm{mg} / 1$ POMP2, were counted and seeded into the upper chamber of the Transwell and the lower chamber was filled with RPMI-1640 supplemented with $10 \%$ FBS. Following incubation at $37^{\circ} \mathrm{C}$ for $24 \mathrm{~h}$, the cells on the inner surface of the upper chamber were removed (6). The cells that had penetrated through the chamber were fixed with methanol and stained with Giemsa, according to the manufacturer's instructions. The cells were then visualized and counted under a microscope (Eclipse TS100; Nikon, Tokyo, Japan); three fields of vision were selected in each experimental condition (26).

Colony formation assay. BGC-823 cells ( 1x10³/well) were seeded into different plates and allowed to adhere overnight. The cells in the polysaccharide groups were incubated at $37^{\circ} \mathrm{C}$ with 100 or $200 \mathrm{mg} / 1$ POMP2 for 10 days, then each plate was washed three times with phosphate-buffered saline (PBS). The colonies were fixed in methanol for $20 \mathrm{~min}$ and stained with $0.5 \%$ crystal violet for $15 \mathrm{~min}$. The colonies were further washed with PBS, observed under the inverted microscope (Eclipse TS100) and images were captured using a CCD color camera (KP-D20AU; Hitachi, Ibaraki, Japan) (27). Each assay was performed three times in two independent experiments.

In vivo antitumor test. An in vivo antitumor assay was performed as described by Miao et al (24), with minor modifications. Male BALB/c (nu/nu) nude mice (4-6 weeks old, 20-22 g, 50 mice; Beijing Vital River Experimental Animal Co., Ltd., Beijing, China) were used to establish a BGC-823 xenograft tumor model. All of the mice were housed in a pathogen-free facility and were given ad libitum access to food and water in sterile conditions. The mice in each group were subcutaneously inoculated with injections of $2 \times 10^{6}$ BGC-823 cells/mouse and monitored daily for tumor growth. Tumor size was determined using micrometer calipers and mice with similar tumor sizes were randomly divided into five groups, each containing five mice. The tumor bearing mice were orally administrated POMP2 at the following doses: 50, 100 and $200 \mathrm{mg} / \mathrm{kg}$. The control group were administered the same volume of PBS and the positive control group were administered $25 \mathrm{mg} / \mathrm{kg} 5$-FU every other day for two weeks. Tumors were removed and weighed after the mice had been sacrificed by cervical dislocation. The tumor volume (TV) of each tumor was calculated using the
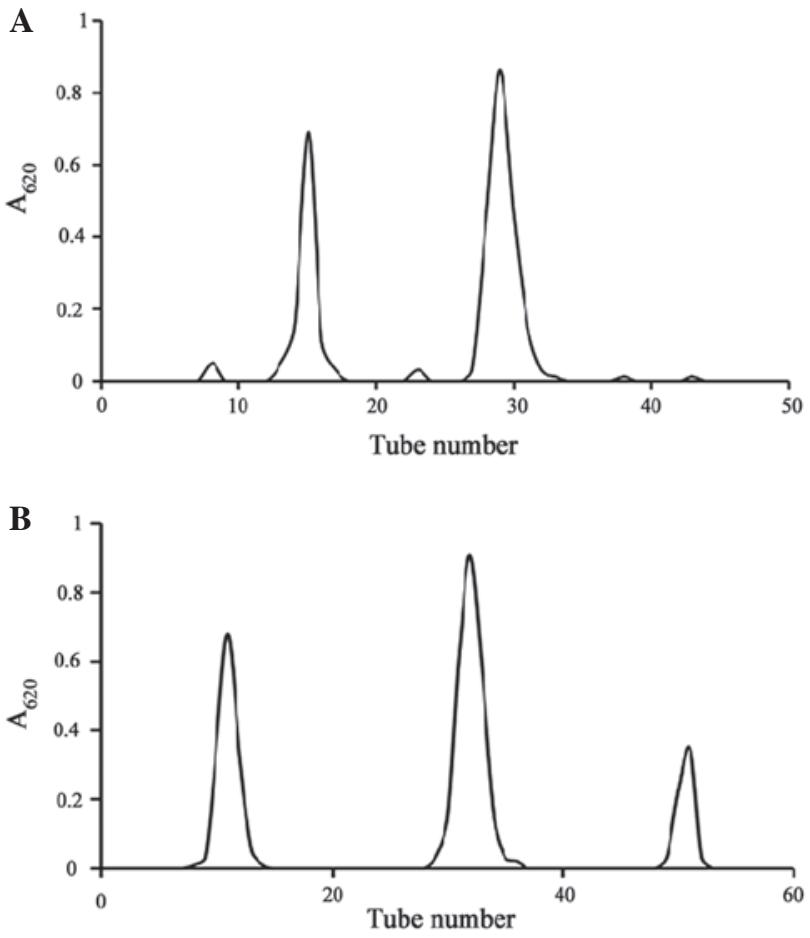

Figure 1. Elution profile of polysaccharides from Pleurotus ostreatus mycelia (A) Sephadex G-200 chromatography. Crude polysaccharides $(0.5 \mathrm{~g})$ were redissolved in distilled water $(10 \mathrm{ml})$ with a concentration of $0.25 \mathrm{~g} / \mathrm{ml}$. The sample was eluted with $0.15 \mathrm{M}$ sodium chloride at a flow rate of $1 \mathrm{ml} / \mathrm{min}$. Fractions were collected and measured for the presence of carbohydrates using the anthrone-sulphuric acid method. (B) DEAE-52 chromatography. Crude polysaccharides were further purified using a DEAE-52 column. The sample was eluted in gradient mode at a flow rate of $1.0 \mathrm{ml} / \mathrm{min}$, with sodium chloride solution used as the mobile phase. All fractions were collected using the automated fraction collector and absorbance (A) was measured at $620 \mathrm{~nm}$, as recommended by the anthrone-sulphuric acid method for polysaccharides.

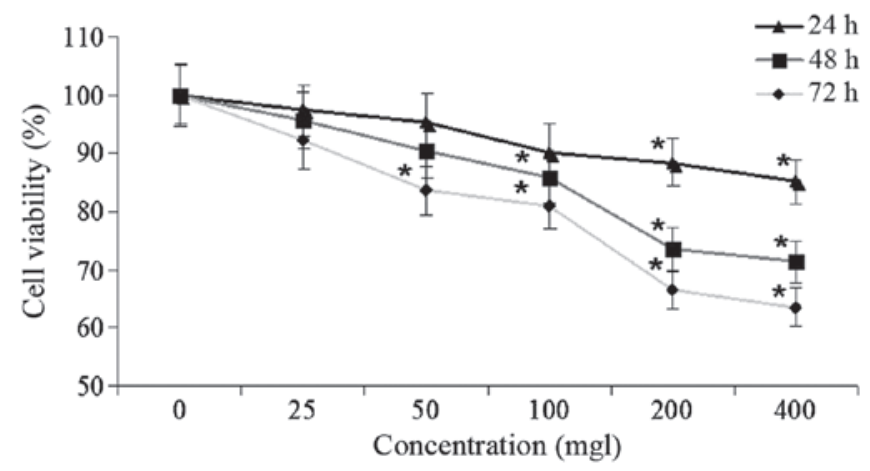

Figure 2. Effects of POMP2 on the proliferation of BGC-823 human gastric cancer cells. Cells were cultured in 96-well plates for $24 \mathrm{~h}$ and then exposed to POMP2 at the indicated concentrations for 24,48 or $72 \mathrm{~h}$. Proliferation was determined using an MTT assay. Values represent the mean \pm standard deviation $(\mathrm{n}=3)$. * $\mathrm{P}<0.05$ vs. control group. POMP2; Pleurotus ostreatus mycelium polysaccharides 2 .

following formula: TV $\left(\mathrm{mm}^{3}\right)=\left(\mathrm{a} \mathrm{x} \mathrm{b}^{2}\right) / 2$, where a $(\mathrm{mm})$ and $\mathrm{b}(\mathrm{mm})$ represent the longest and shortest tumor diameter, respectively.

Statistical analysis. All statistical analyses were performed using SPSS 18.0 (International Business Machines, Armonk, $\mathrm{NY}$, USA). The data are presented as the mean \pm standard 
A

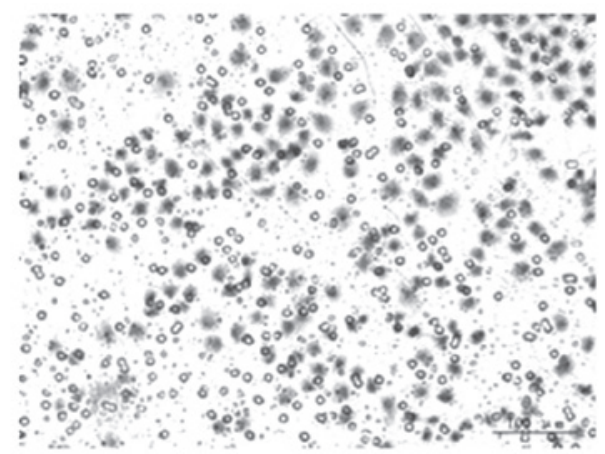

C

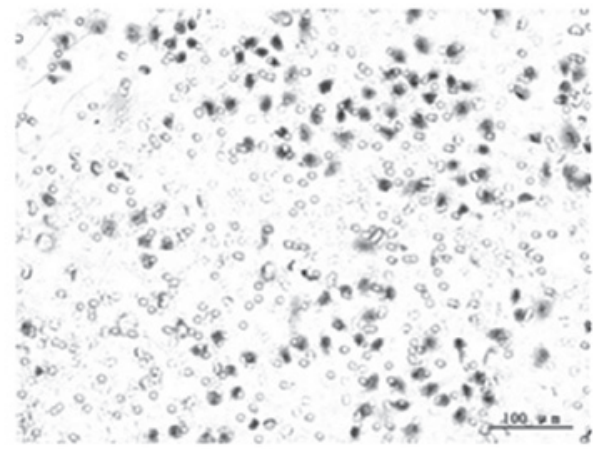

B

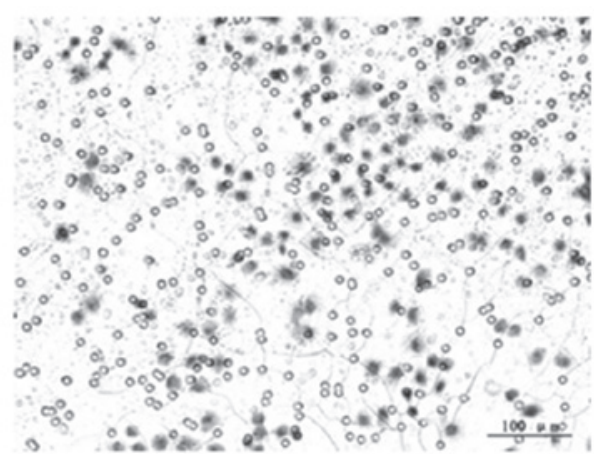

D

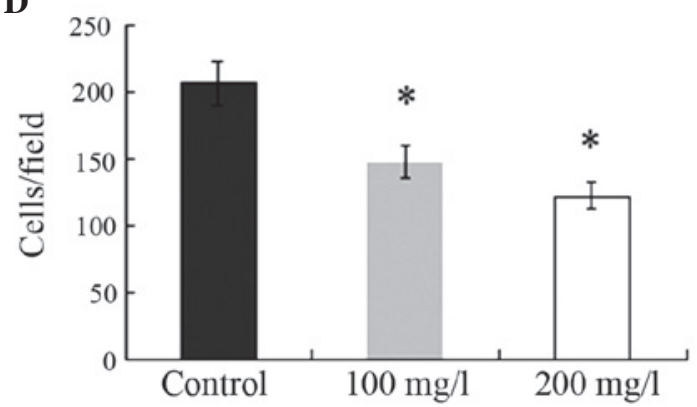

Figure 3. Effects of POMP2 on the migration of BGC-823 human gastric cancer cells, as determined using a Transwell system. BGC-823 cells treated with serum free RPMI-1640 medium or POMP2 were seeded into the upper chamber of a Transwell at a density of $1 \times 10^{5}$ cells $/ \mathrm{ml}$ and allowed to migrate through the pores for $24 \mathrm{~h}$. The number of cells per field that had migrated to the bottom surface of the filter was then counted. (A) Control-treated cells, (B) cells treated with $100 \mathrm{mg} / 1$ POMP2 and (C) cells treated with $200 \mathrm{mg} / 1$ POMP2. (D) Quantification of migrated cells. Values represent the mean \pm standard deviation of three repeats from one independent study. ${ }^{*} \mathrm{P}<0.05$ vs. control group. POMP2; Pleurotus ostreatus mycelium polysaccharides 2.

deviation. One-way analysis of variance was used to perform statistical comparisons. Randomized block analysis of variance and the Students-Newman-Keuls method were selected for intergroup comparisons. $\mathrm{P}<0.05$ was considered to indicate a statistically significant difference between values.

\section{Results}

Isolation, purification and characterization of polysaccharide. The crude polysaccharides extracted from the mycelium of Pleurotus ostreatus were collected and sequentially purified through Sephadex G200 and DEAE-52 columns. As shown in Fig. 1, three fractions: POMP1, POMP2 and POMP3, were separated. The main fraction, POMP2, was selected for subsequent analyses due to its higher activity of antiproliferation measured by MTT method (data not shown). POMP2 appeared as a white powder. The average molecular weight of POMP2 was calculated as $29 \mathrm{kDa}$ by HPGPC, according to a calibration curve with standard dextran and glucose. No absorbance was detected by a spectrophotometer at 280 and $260 \mathrm{~nm}$, thus indicating that the preparation of POMP2 contained no protein or nucleic acids and was a homogeneous polysaccharide.

In vitro antitumor activity. BGC-823 cells were incubated with various concentrations of POMP2 $(25,50,100$, 200 and $400 \mathrm{mg} / \mathrm{l}$ ) for various durations (24, 48 and $72 \mathrm{~h}$ ). Subsequently, cell survival was measured using the MTT method. As shown in Fig. 2, POMP2 inhibited the proliferation of BGC-823 cells in a time- and concentration-dependent manner; significant inhibition was exhibited at various concentrations following 24,48 and $72 \mathrm{~h}$ of treatment compared with the control group $(\mathrm{P}<0.05)$. At the highest concentration (400 mg/l), the rate of inhibition was $35.6 \%$ following $72 \mathrm{~h}$.

Invasiveness of BGC-823 cells is inhibited by POMP2. Metastasis is the predominant cause of cancer-associated mortality. The Transwell migration assay is suitable for cancer cells and is used to evaluate the invasive and migratory ability of cells into distal organs. To investigate the effects of POMP2 on the migration of BGC-823 cells, the migratory behavior of the cells was determined using a Transwell assay. The number of POMP2-treated cells that were able to migrate across the membrane was markedly reduced compared with the control cells (Fig. 3A-C). These results suggest that POMP2 was able to significantly inhibit the invasiveness of BGC-823 cells $(\mathrm{P}<0.05)$ (Fig. 3D).

Treatment with POMP2 reduces colony formation. The number of BGC-823 colonies formed in the presence of POMP2 was significantly reduced compared with the negative control group; representative images are shown in Fig. 4. When the cells were treated with 100 and $200 \mathrm{mg} / \mathrm{l}$ POMP2 for $72 \mathrm{~h}$ there was a highly significant reduction in colony formation compared with the negative control group $\left({ }^{*} \mathrm{P}<0.05\right)$ (Fig. 4D).

Effects of bioactive POMP2 on tumor growth in vivo. Based on the in vitro results of the present study, POMP2 was used for in vivo antitumor experiments to further explore whether it possessed a growth inhibitory effect on tumor growth in mice. The effects of POMP2 on the growth of primary tumor xenografts in nude mice were examined. All mice survived 
A

C
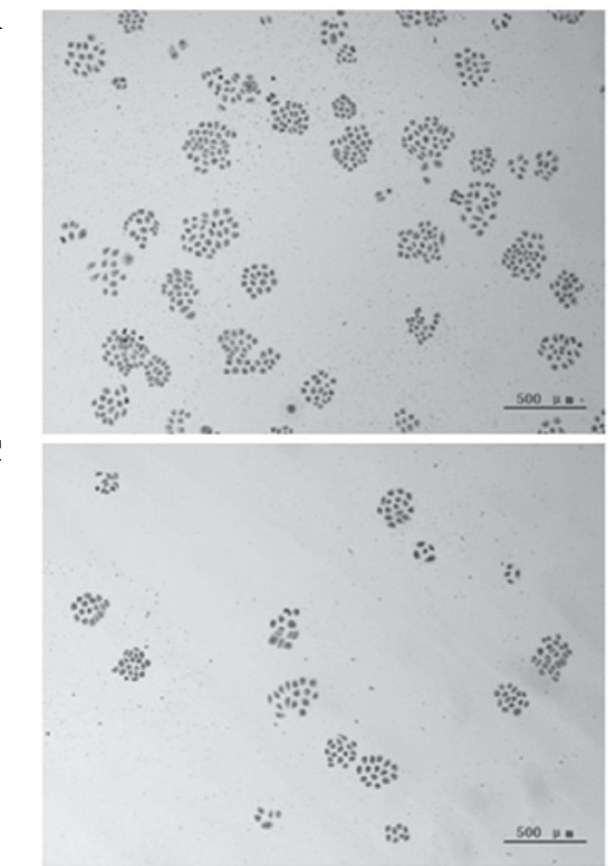

B

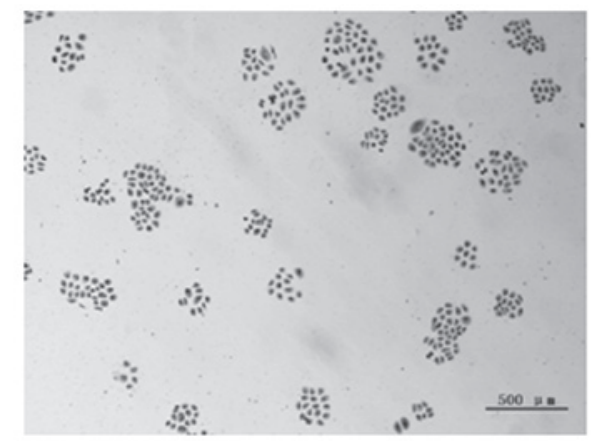

D

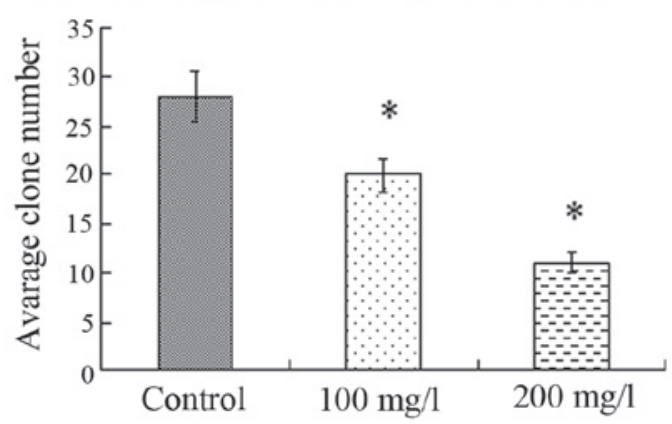

Figure 4. Treatment with POMP2 inhibits colony formation in BGC-823 human gastric cancer cells. Colony formation was measured using a plate colony formation assay. BGC-823 cells were treated with the indicated concentrations of POMP2 for 10 days and the colonies were fixed, stained and visualized under an inverted microscope. (A) Control-treated cells, (B) cells treated with $100 \mathrm{mg} / 1$ POMP2 and (C) cells treated with $200 \mathrm{mg} / 1 \mathrm{POMP} 2$. (D) Quantitative data for the number of colonies formed are presented as the mean \pm standard deviation of three repeats from one independent study. ${ }^{*} \mathrm{P}<0.05 \mathrm{vs}$. control group. POMP2; Pleurotus ostreatus mycelium polysaccharides 2 .
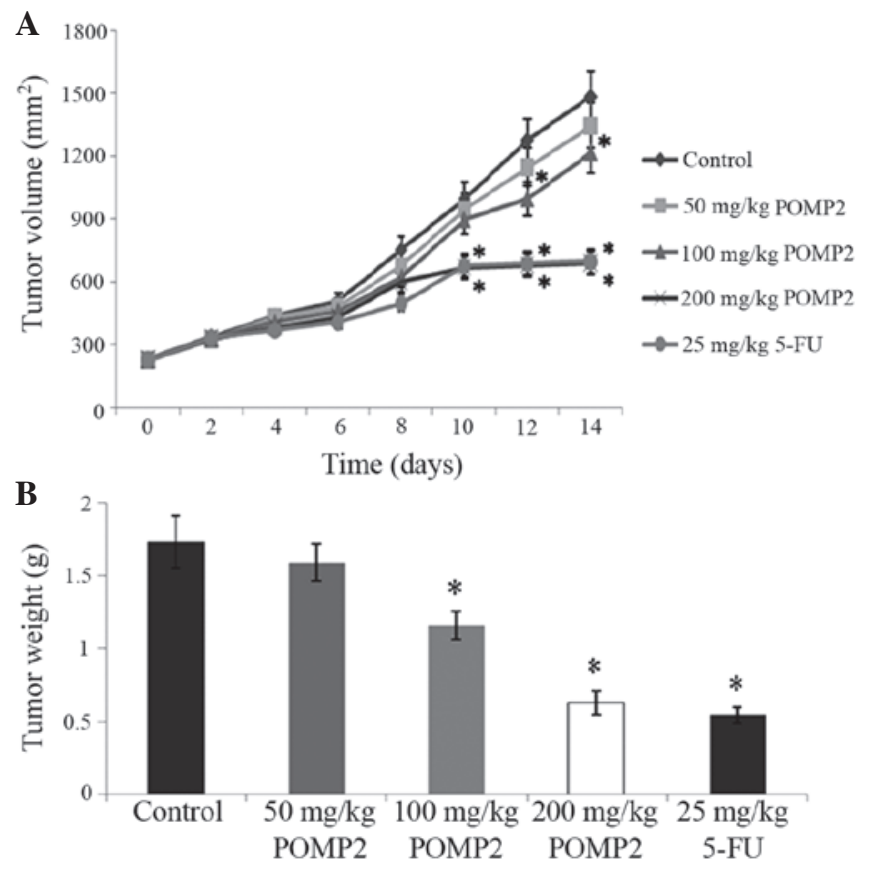

Figure 5. Antitumor effects of POMP2 in vivo. (A) Effects of POMP2 on tumor volume. Mice in each treatment group were subcutaneously inoculated with $2 \times 10^{6}$ BGC-823 human gastric cancer cells/mouse and monitored daily for tumor growth. (B) Effects of POMP2 on tumor weight. Following sacrifice, tumors were removed and weighed. Tumor volume was calculated as follows: Tumor volume $\left(\mathrm{mm}^{3}\right)=\left(\mathrm{a} \mathrm{x} \mathrm{b}^{2}\right) / 2$, where $\mathrm{a}(\mathrm{mm})$ and $\mathrm{b}(\mathrm{mm})$ represent the longest and shortest diameter, respectively. ${ }^{*} \mathrm{P}<0.05$ vs. control group. POMP2; Pleurotus ostreatus mycelium polysaccharides 2; 5-FU, 5-fluorouracil.

the experiment and the tumor xenografts were shown to be successful. As shown in Fig. 5, significant decreases in tumor weight and volume were observed following treatment with
100 and $200 \mathrm{mg} / \mathrm{kg}$ POMP2 compared with the control group $(\mathrm{P}<0.05)$. These results suggested that POMP2 may be able to potently suppress tumor growth in mice bearing BGC-823 xenografts.

\section{Discussion}

Gastric cancer is a major global public health problem, particularly in Asian and Eastern European countries, where the rate of incidence is 6-8 times greater than in Western countries (28). Even in patients with operable tumors, the proportion of long-term survivors is $25 \%$ worldwide (29). Chemotherapy is widely used to treat advanced gastric cancer (30). 5-FU is currently considered an important drug in clinical chemotherapeutic treatment for gastrointestinal cancers, but it is not efficient for gastric cancer therapy when it is used alone (31). Furthermore, the presence of gastric cancer cells that are resistant to current chemotherapeutic drugs results in a lack of curative effects (32). The use of natural products as biological drugs may be an effective method for treating gastric cancer (33). In particular, polysaccharides extracted from mushrooms have gained attention. Numerous polysaccharides have been isolated from the fruit body of fungi; however, it may take more time and energy to obtain the fruit body, resulting in a lower efficiency compared with extracting polysaccharides from mycelia (34). With regards to antitumor mechanism, previous studies have indicated that polysaccharides were able to directly inhibit tumor activity (35) and some reports have demonstrated that numerous types of polysaccharide exhibit significant apoptosis-inducing activities $(11,36)$. In addition, previous studies have indicated that polysaccharides may inhibit cancer by stimulating the immune system $(13,32)$. 
Pleurotus ostreatus is a well-known, traditional edible fungus that is consumed in China due to its nutritional properties. Previous studies have shown that Pleurotus ostreatus contains numerous classes of compounds, including extracellular enzymes, phenols, flavoring agents and polysaccharides (37). Polysaccharides may be obtained from both the fruit body and the mycelia of fungi (38). Due to the limited supply of fruit body, cultivation of its mycelial form in controlled conditions may be another resource of polysaccharides (39). The anticancer polysaccharide fractions may be clinically used to treat various types of cancer. However, there are currently few reports of polysaccharides isolated from Pleurotus ostreatus mycelia exhibiting antitumor properties in gastric cancer. The present study successfully isolated and purified POMP2 from Pleurotus ostreatus mycelia and characterized its anticancer properties. The inhibitory effects of POMP2 on gastric cancer cells were investigated in vitro and in vivo. Results of an MTT assay demonstrated that POMP2 significantly inhibited the proliferation of BGC-823cells, which indicated that POMP2 had a cytotoxic effect on BGC-823 cells. The colony formation assay is another in vitro cell survival assay, based on the ability of a single cell to grow into a colony (40). In the present study, $100 \mathrm{mg} / 1$ POMP2 resulted in a significant reduction in colony formation in BGC-823 cells. The transition of tumor cells from benign tumor growth to malignancy is characterized by their ability to invade the surrounding tissue (41). Metastasis is one of the predominant causes of cancer-associated mortality (41); therefore, the present study investigated the migratory ability of BGC-823 cells treated with POMP2. A Transwell migration assay was used to assess the ability of POMP2 to inhibit metastasis of cancer cells and the results demonstrated that cells treated with POMP2 for $24 \mathrm{~h}$ exhibited significantly reduced migration, as compared with the control cells.

Based on the initial screening results, the present study investigated the antitumor activity of POMP2 in BGC-823 cancer cell-engrafted mice. The results demonstrated that tumor weight and volume were markedly suppressed following POMP2 treatment for 2 weeks in tumor-bearing mice. The results of these in vivo and in vitro studies provided evidence for the potential use of POMP2 as an anticancer agent against gastric cancer (24).

In conclusion, the results of the present study indicated that POMP2, a polysaccharide isolated from Pleurotus ostreatus mycelia, is a natural product that may inhibit gastric cancer cell growth in vitro and in vivo, in a dose- and time-dependent manner. Based on these results, it may be speculated that POMP2 could be used as a potential therapeutic agent against gastric cancer. The present study is a preliminary study that aimed to prove the antitumor effects of POMP2; therefore, further research regarding the precise mechanisms underlying its anticancer actions is required.

\section{Acknowledgements}

The present study was supported by the National Natural Science Foundation of China (grant no. 31240005), the Program for Liaoning Excellent Talents in University (grant no. LJQ2013002), the Agriculture Research Program of Science and Technology Department of Liaoning Province,
China (grant nos. 2011211001 and 2009209001) the Startup Foundation for Doctors of Liaoning University and the Scientific Research Fund of Liaoning Provincial Education Department (grant no. L2014007).

\section{References}

1. Jemal A, Bray F, Center MM, et al: Global cancer statistics. CA Cancer J Clin 61: 69-90, 2011.

2. Shiotani A, Cen P and Graham DY: Eradication of gastric cancer is now both possible and practical. Semin Cancer Biol 23: 492-501, 2013.

3. Melton SD, Genta RM and Souza RF: Biomarkers and molecular diagnosis of gastrointestinal and pancreatic neoplasms. Nat Rev Gastroenterol Hepatol 7: 620-628, 2010.

4. Correa P and Houghton J: Carcinogenesis of Helicobacter pylori. Gastroenterology 133: 659-672, 2007.

5. Ferlay J, Shin HR, Bray F, et al: Estimates of worldwide burden of cancer in 2008: GLOBOCAN 2008. Int J Cancer 127: 2893-2917, 2010.

6. Crew KD and Neugut AI: Epidemiology of gastric cancer. World J Gastroenterol 12: 354-362, 2006.

7. Shi Y and Zhou Y: The role of surgery in the treatment of gastric cancer. J Surg Oncol 101: 687-692, 2010.

8. Yamashita K, Sakuramoto S, Nemoto M, et al: Trend in gastric cancer: 35 years of surgical experience in Japan. World J Gastroenterol 17: 3390-3397, 2011.

9. Wasser SP: Medicinal mushrooms as a source of antitumor and immunomodulating polysaccharides. Appl Microbiol Biotechnol 60: 258-274, 2002.

10. Cao X, Liu R, Liu J, et al: A novel polysaccharide from Lentinus edodes Mycelia exhibits potential antitumor activity on laryngeal squamous cancer cell line Hep-2. Appl Biochem Biotechnol 171: 1444-1453, 2013.

11. Zhang M, Cui SW, Cheung PCK and Wang Q: Antitumor polysaccharides from mushrooms: A review on their isolation process, structural characteristics and antitumor activity. Trends Food Sci Technol 18: 4-19, 2007.

12. Zong A, Cao H and Wang F: Anticancer polysaccharides from natural resources: A review of recent research. Carbohydr Polym 90: 1395-1410, 2012.

13. Liu JJ, Huang TS, Hsu ML, et al: Antitumor effects of the partially purified polysaccharides from Antrodia camphorata and the mechanism of its action. Toxicol Appl Pharmacol 201: 186-193, 2004.

14. Ahmad MS, Ahmad S, Gautam B and Afzal M: Antigenotoxic and anticlastogenic potential of Agaricus bisporus against MMS induced toxicity in human lymphocyte cultures and in bone marrow cells of mice. Egypt J Med Hum Genet 14: 395-402, 2013.

15. Lavi I, Friesem D, Geresh S, et al: An aqueous polysaccharide extract from the edible mushroom Pleurotus ostreatus induces anti-proliferative and pro-apoptotic effects on HT-29 colon cancer cells. Cancer Lett 244: 61-70, 2006.

16. Gao T, Bi H, Ma S and Lu J: Structure elucidation and antioxidant activity of a novel $\alpha-(1-->3),(1-->4)-D$-glucan from Aconitum kusnezoffii Reichb. Int J Biol Macromol 46: 85-90, 2010.

17. Kalmis E, Azbar N, Yildiz H and Kalyoncu F: Feasibility of using olive mill effluent (OME) as a wetting agent during the cultivation of oyster mushroom, Pleurotus ostreatus, on wheat straw. Bioresour Technol 99: 164-169, 2008.

18. Jayakumar T, Thomas PA and Geraldine P: Protective effect of an extract of the oyster mushroom, Pleurotus ostreatus, on antioxidants of major organs of aged rats. Exp Gerontol 42: 183-191, 2007.

19. Tong H, Xia F, Feng K, et al: Structural characterization and in vitro antitumor activity of a novel polysaccharide isolated from the fruiting bodies of Pleurotus ostreatus. Bioresour Technol 100: 1682-1686, 2009.

20. Facchini JM, Alves EP, Aguilera C, et al: Antitumor activity of Pleurotus ostreatus polysaccharide fractions on Ehrlich tumor and Sarcoma 180. Int J Biol Macromol 68: 72-77. 2014.

21. Staub AM: Removal of proteins: Sevag Method. In: Methods Carbohydr Chem. Whistler RL (ed). Vol 5. Academic Press, Inc., New York, pp5-6, 1965.

22. Jeff IB, Yuan X, Sun L, et al: Purification and in vitro anti-proliferative effect of novel neutral polysaccharides from Lentinus edodes. Int J Biol Macromol 52: 99-106, 2013. 
23. DuBois M, Gilles KA, Hamilton JK, et al: Colorimetric method for determination of sugar and related substances. Anal Chem 28: 350-356, 1956.

24. Miao S, Mao X, Pei R, et al: Antitumor activity of polysaccharides from Lepista sordida against laryngocarcinoma in vitro and in vivo. Int J Biol Macromol 60: 235-240, 2013.

25. Cao W, Li XQ, Wang X, et al: A novel polysaccharide, isolated from Angelica sinensis (Oliv.) Diels induces the apoptosis of cervical cancer HeLa cells through an intrinsic apoptotic pathway. Phytomedicine 17: 598-605, 2010.

26. Chen D, Yao WJ, Zhang XL, et al: Effects of Gekko sulfated polysaccharide-protein complex on human hepatoma SMMC-7721 cells: Inhibition of proliferation and migration. J Ethnopharmacol 127: 702-708, 2010.

27. Wang J, Liu W, Zhao Q, et al: Synergistic effect of 5-fluorouracil with gambogic acid on BGC-823 human gastric carcinoma. Toxicology 256: 135-140, 2009.

28. Bae JS, Jang KH and Jin HK: Effects of natural polysaccharides on the growth and peritoneal carcinomatosis of human gastric adenocarcinoma in a nude mouse model. Cancer Lett 235: 60-68, 2006.

29. Cervantes A, Roda D, Tarazona N, et al: Current questions for the treatment of advanced gastric cancer. Cancer Treat Rev 39: 60-67, 2013.

30. Ajani JA: Chemotherapy for gastric carcinoma: New and old options. Oncology (Williston Park) 12 (Suppl 7): 44-47, 1998.

31. Wöhrer SS, Raderer M and Hejna M: Palliative chemotherapy for advanced gastric cancer. Ann Oncol 15: 1585-1595, 2004

32. Li R, Chen WC, Wang WP, et al: Extraction, characterization of Astragalus polysaccharides and its immune modulating activities in rats with gastric cancer. Carbohydr Polym 78: 738-742, 2009.
33. Zhang Y, Wang Q, Wang T, et al: Inhibition of human gastric carcinoma cell growth in vitro by a polysaccharide from Aster tataricus. Int J Biol Macromol 51: 509-513, 2012.

34. Ulziijargal E, Yang JH, Lin LY, et al: Quality of bread supplemented with mushroom mycelia. Food Chem 138: 70-76, 2013.

35. Wang YY,Khoo KH,Chen ST, et al: Studies on the immuno-modulating and antitumor activities of Ganoderma lucidum (Reishi) polysaccharides: Functional and proteomic analyses of a fucose-containing glycoprotein fraction responsible for the activities. Bioorg Med Chem 10: 1057-1062, 2002.

36. Gan D, Ma L, Jiang C, et al: Production, preliminary characterization and antitumor activity in vitro of polysaccharides from the mycelium of Pholiota dinghuensis Bi. Carbohydr Polym 84: 997-1003, 2011

37. Gern RM, Wisbeck E, Rampinelli JR, et al: Alternative medium for production of Pleurotus ostreatus biomass and potential antitumor polysaccharides. Bioresour Technol 99: 76-82, 2008.

38. Xia F, Fan J, Zhu M and Tong H: Antioxidant effects of a water-soluble proteoglycan isolated from the fruiting bodies of Pleurotus ostreatus. J Taiwan Inst Chem Eng 42: 402-407, 2011.

39. Devi KS, Roy B, Patra P, et al: Characterization and lectin microarray of an immunomodulatory heteroglucan from Pleurotus ostreatus mycelia. Carbohydr Polym 94: 857-865, 2013.

40. Subramaniam V, Ace O, Prud'homme GJ and Jothy S: Tranilast treatment decreases cell growth, migration and inhibits colony formation of human breast cancer cells. Exp Mol Pathol 90: 116-122, 2011.

41. Liu J, Guo Y, Fu S, et al: Hypomethylation-induced expression of S100A4 increases the invasiveness of laryngeal squamous cell carcinoma. Oncol Rep 23: 1101-1107, 2010. 